\title{
p85a promotes nucleolin transcription and subsequently enhances EGFR mRNA stability and EGF-induced malignant cellular transformation
}

\author{
Qipeng Xie ${ }^{1, *}$, Xirui Guo ${ }^{1, *}$, Jiayan Gu ${ }^{1}$, Liping Zhang ${ }^{1}$, Honglei Jin ${ }^{1,2}$, Haishan Huang ${ }^{1}$, \\ Jingxia $\mathrm{Li}^{2}$, Chuanshu Huang ${ }^{1,2}$ \\ ${ }^{1}$ Zhejiang Provincial Key Laboratory for Technology and Application of Model Organisms, School of Life Sciences, Wenzhou \\ Medical University, Wenzhou, Zhejiang, 325035, China \\ ${ }^{2}$ Nelson Institute of Environmental Medicine, New York University School of Medicine, Tuxedo, NY 10987, USA \\ *These authors contributed equally to this work
}

Correspondence to: Chuanshu Huang, e-mail: huangchuanshu@hotmail.com

Keywords: PI3K, p85a, EGFR, nucleolin, cell transformation

Received: December 24, $2015 \quad$ Accepted: January 16, 2016

Published: February 24, 2016

\section{ABSTRACT}

p85a is a regulatory subunit of phosphatidylinositol 3-kinase (PI3K) that is a key lipid enzyme for generating phosphatidylinositol 3, 4, 5-trisphosphate, and subsequently activates signaling that ultimately regulates cell cycle progression, cell growth, cytoskeletal changes, and cell migration. In addition to form a complex with the p110 catalytic subunit, p85a also exists as a monomeric form due to that there is a greater abundance of p85a than p110 in many cell types. Our previous studies have demonstrated that monomeric p85a exerts a pro-apoptotic role in UV response through induction of TNF-a gene expression in PI3K-independent manner. In current studies, we identified a novel biological function of $\mathbf{p 8 5 a}$ as a positive regulator of epidermal growth factor receptor (EGFR) expression and cell malignant transformation via nucleolin-dependent mechanism. Our results showed that p85a was crucial for EGFR and nucleolin expression and subsequently resulted in an increase of malignant cellular transformation by using both specific knockdown and deletion of p85a in its normal expressed cells. Mechanistic studies revealed that p85a upregulated EGFR protein expression mainly through stabilizing its mRNA, whereas nucleolin (NCL) was able to bind to egfr mRNA and increase its mRNA stability. Consistently, overexpression of NCL in p85a-/- cells restored EGFR mRNA stabilization, protein expression and cell malignant transformation. Moreover, we discovered that p85a upregulated NCL gene transcription via enhancing C-Jun activation. Collectively, our studies demonstrate a novel function of $\mathrm{p85a}$ as a positive regulator of EGFR mRNA stability and cell malignant transformation, providing a significant insight into the understanding of biomedical nature of p85a protein in mammalian cells and further supporting that p85a might be a potential target for cancer prevention and therapy.

\section{INTRODUCTION}

The epidermal growth factor receptor (EGFR), also called ErbB1, is first identified member of the subfamily of tyrosine kinase receptors [1]. The ligands of EGFR include EGF, TGFa, amphiregulin, heparin-binding EGF-like factor (HB-EGF), betacellulin (BTC) and epiregulin [2-4]. Ligand binding and activation leads to EGFR dimerization and auto-phosphorylation of tyrosine residues in the $\mathrm{C}$-terminal region that provide docking sites for Src homology 2 or phosphotyrosine-binding domaincontaining signaling molecules [5]. The EGFR downstream regulated signaling pathways include PI3K/Akt axis and Ras/Raf/MAPK (ERK, JNK and p38) axis [6]. EGFR plays an important role in extensive crosstalk among multiple signaling pathways and regulation of various cell functions [7]. EGFR also plays a significant role in tumor development and progression, including cell proliferation, regulation of apoptotic cell death, angiogenesis and metastatic spread. In most cell types, EGFR is found in 
amounts varying from $2 \times 10^{4}$ to $2 \times 10^{5}$ receptors per cell. Overexpression of EGFR up to $>10^{6}$ receptors per cell has been described for many cancer types, such as in the lung, head and neck, colon, pancreas, breast, ovary, bladder and kidney, and in gliomas [8-11]. Moreover, several studies demonstrate that EGFR expression correlates with the reduced disease-free and overall survival, poor prognosis, increased risk of disease recurrence, advanced tumor stage, and increased risk of metastasis [12].

EGFR expression in human tissues could be regulated at levels of gene amplification, mRNA transcription and degradation, protein translation and degradation $[13,14]$. EGFR mRNA is central to the flow of genetic information, and regulation of mRNA stability is a powerful mechanism for altering gene expression, and is regulated by multiple proteins [15-17]. Microarray analyses suggest that approximately $40 \%-50 \%$ of changes in gene expression in response to extracellular treatment occurred due to altered mRNA stability [18, 19]. The defect in regulation of mRNA stability might lead to complicated disorders, including cancers [18].

The class I phosphoinositide 3-kinase (PI3K) is heterodimer lipid enzyme that is composed of a catalytic (p110) and a regulatory (p85) subunit. Upon activation, PI3K produces a key second messenger lipid, phosphatidylinositol 3, 4, 5-trisphosphate (PIP3), and regulates many cellular functions, such as cell growth and survival $[20,21]$. The regulatory p85 subunit has five variants (p85 $\alpha, \mathrm{p} 55 \alpha, \mathrm{p} 50 \alpha, \mathrm{p} 85 \beta$, and p55 $\gamma$ ) [20, 22]. Of these isoforms, $\mathrm{p} 85 \alpha$ is predominantly and ubiquitously expressed in most tissues and is thought to be the major element of response to most stimuli [23]. In addition to forming a complex with the p110 catalytic subunit, p85 $\alpha$ also exists in a monomeric form due to the greater abundance of p85 $\alpha$ than of p110 in many cell types [24]. The monomeric p85 $\alpha$ is able to act as a mediator for transducing the insulin-like growth factor 1-dependent cellular response [25] and is also involved in the apoptotic response under oxidative stress in a PI3K-independent manner. Our previous studies demonstrate that $\mathrm{p} 85 \alpha$ mediates apoptotic response following UV radiation in a PI3K-independent manner [26]. However, the role of p $85 \alpha$ alone in regulation of EGFR expression and its related mechanisms has not been explored yet. Here we reported that $\mathrm{p} 85 \alpha$ was able to regulate EGFR expression by increasing in egfr mRNA stability and EGF-induced cell malignant transformation. We further showed that NCL expression mediated by $\mathrm{p} 85 \alpha$ was able to bind with egfr mRNA, which protected egfr mRNA from degradation.

\section{RESULTS}

\section{p85 $\alpha$ was essential for EGFR expression and EGF-induced cell transformation}

Many tumors exhibit an increased activation of PI3K signaling pathway, while p $85 \alpha$ regulates multiple cellular biological functions either through PI3Kdependent or -independent manners $[25,26]$. To determine the role of $\mathrm{p} 85 \alpha$ in the regulation of cell transformation, we first utilized EGF as a tumor promoter to establish an EGF-induced cell malignant transformation experimental system [27] and consequently evaluated EGF-induced anchorage-independent growth abilities in $\mathrm{p} 85 \alpha+/+$ and $\mathrm{p} 85 \alpha-1-$ cells. The results showed that knockout of $\mathrm{p} 85 \alpha$ led to a completely deficiency of anchorage-independent growth upon EGF exposure in comparison to that in p $85 \alpha+/+$ cells under same experimental conditions (Figure $1 \mathrm{~A}$ and $1 \mathrm{~B}$ ), suggesting that $\mathrm{p} 85 \alpha$ was crucial for EGFinduced cell malignant transformation. To elucidate the molecular mechanism underlying $\mathrm{p} 85 \alpha$ regulation of EGFinduced cell transformation, we determined EGFR protein expression in both p $85 \alpha+/+$ and p $85 \alpha-/-$ cells. EGFR protein expression was found to be almost completely impaired in p85 $\alpha^{-} /-$cells (Figure 1C), which is consistent with the cell responses of anchorage-independent growth abilities following EGF treatment and further revealing that $\mathrm{p} 85 \alpha$ is critical for EGFR expression in addition to its requirement for cell malignant transformation after EGF treatment. This notion was greatly strengthened by the results obtained from using a specific short hairpin RNAs (shRNAs) targeting $\mathrm{p} 85 \alpha$ to knockdown its expression in p85a+/+ cells. As shown in Figure 1D, knockdown of p85 $\alpha$ expression by its shRNA impaired EGFR expression as compared with their scramble control transfectants, p85 $\alpha+/+$ (Nonsense). Moreover, we constructed a pEGFP-EGFR and stably transfected it into p85 $\alpha^{-1} /-$ cells to restore EGFR expression. The stable transfectants p $85 \alpha-1-$ (EGFR-GFP) and its scramble control p $85 \alpha^{-1-}$ (Vector) were established as shown in Figure 1E. The results from determination of EGFinduced transformation indicated that knockdown of $\mathrm{p} 85 \alpha$ in $\mathrm{p} 85 \alpha+/+(\operatorname{shp} 85 \alpha-1)$ cells significantly attenuated the cell malignant transformation upon EGF $(60 \mathrm{ng} / \mathrm{ml})$ treatment compared with p85a+/+ (Nonsense) cells (Figure $1 \mathrm{~F}$ and $1 \mathrm{G}$ ), whereas overexpression of EGFRGFP in $p 85 \alpha-/-$ (EGFR-GFP) cells profoundly promoted the cell malignant transformation upon EGF treatment in comparison to that in $\mathrm{p} 85 \alpha-/-$ (Vector) (Figure 1H and 1I). These results demonstrate that EGFR serves as an important downstream mediator responsible for $\mathrm{p} 85 \alpha$ promoting cell transformation following EGF treatment.

\section{p85 $\alpha$ mediated EGFR mRNA stabilization}

EGFR expression is delicately regulated at multiple levels, including transcriptional, post-transcriptional, 
translational, and post-translational levels [28]. To define the mechanism underlying $\mathrm{p} 85 \alpha$ regulation of EGFR expression, we first compared EGFR mRNA levels between p $85 \alpha+/+$ and p $85 \alpha-/-$ cells, and we found that EGFR mRNA expression was profoundly downregulated in $\mathrm{p} 85 \alpha-/-$ cells as compared with that in p85a+/+ cells (Figure 2A). This finding was further supported by the results obtained from utilization of shRNA specific targeting p85 $\alpha$, showing that EGFR mRNA expression was dramatically inhibited in $\mathrm{p} 85 \alpha$ knockdown transfectant, $\mathrm{p} 85 \alpha+/+(\operatorname{shp} 85 \alpha-1)$, in comparison to the scramble transfectant, $\mathrm{p} 85 \alpha+/+$ (Nonsense) (Figure 2B). To test whether p85 $\alpha$ regulated EGFR mRNA transcription, EGFR promoter-driven luciferase reporter was transfected into both $\mathrm{p} 85 \alpha+/+$ cells and $\mathrm{p} 85 \alpha-/-$ cells and the promoter transcription activity was compared between the two transfectants. As shown in Figure 2C, opposite to EGFR mRNA expression, EGFR promoter-driven luciferase reporter transcription activity in p $85 \alpha-/-$ cells was significant higher than that observed in p85a+/+ cells (Figure 2C), excluding the possibility that p $85 \alpha$ positively regulates EGFR mRNA transcription. Thus, we next determined the possibility of $\mathrm{p} 85 \alpha$ regulation of EGFR mRNA stability. The p $85 \alpha+/+$ and $\mathrm{p} 85 \alpha-/-$ cells were treated with the de novo mRNA synthesis inhibitor actinomycin D (Act D), and the decay rate of EGFR mRNA was assessed by RT-PCR (Top panel of Figure 2D). To made the comparable of mRNA levels between p $85 \alpha+/+$ and p $85 \alpha-/-$ cells, we loaded more total cDNA in all samples of $\mathrm{p} 85 \alpha-/-$ cells for RT-PCR than those in $\mathrm{p} 85 \alpha+/+$ cells (as seen in gadph levels of bottom panel). As shown in Figure 2D, EGFR mRNA stability was dramatically reduced in $\mathrm{p} 85 \alpha-1-$ cells as compared with that observed in p85 $\alpha+/+$ cells. Our results indicate that $\mathrm{p} 85 \alpha$ is crucial for EGFR mRNA stabilization.
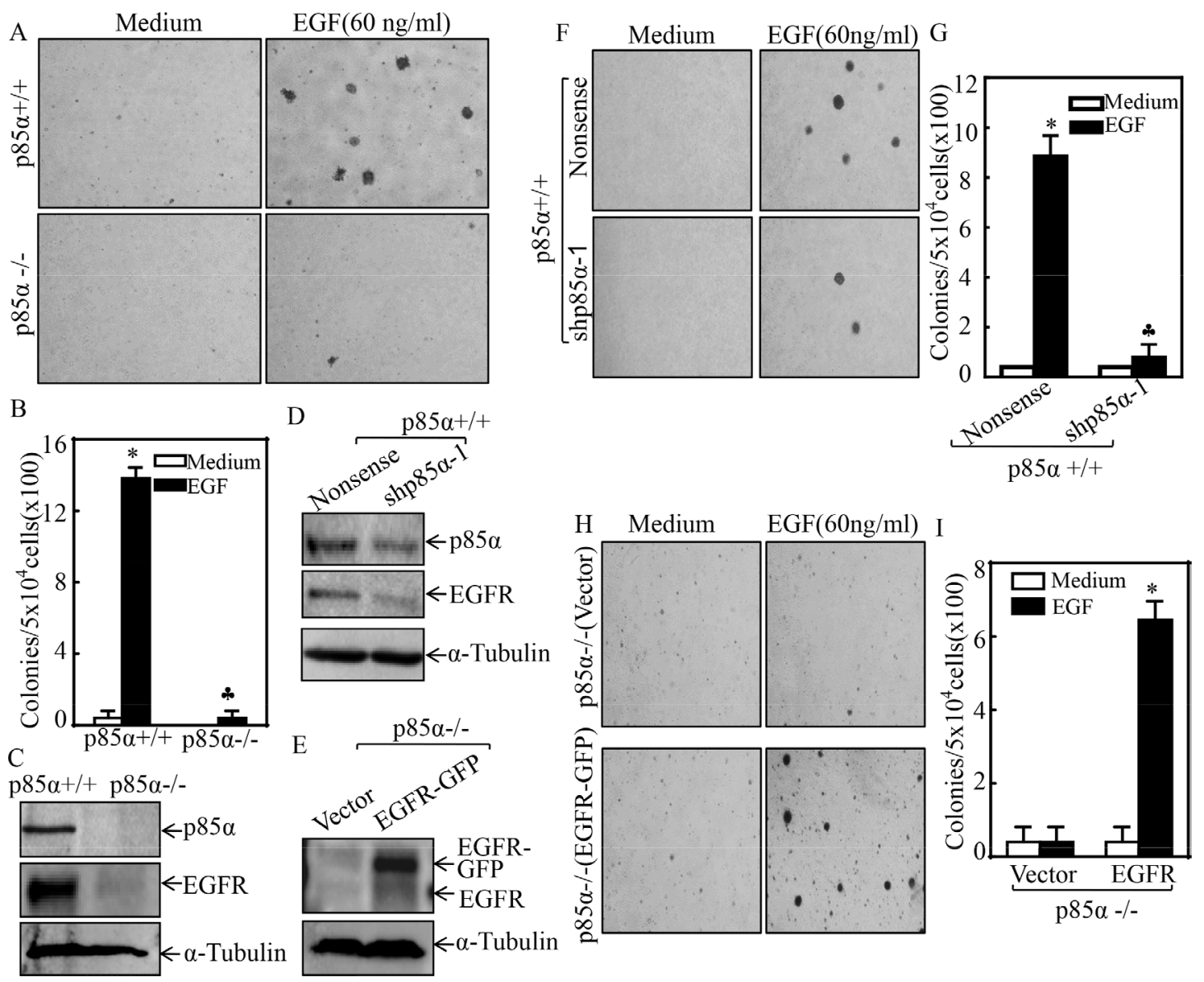

Figure 1: p85 $\alpha$ was required for EGFR expression and EGF-induced malignant cell transformation. $\left(\right.$ A \& B) $5 \times 10^{4}$ cells of $\mathrm{p} 85 \alpha+/+$ and $\mathrm{p} 85 \alpha-/-$ cells were subjected to soft agar assay in presence of EGF (60 ng/ml). The images were captured under inverted microscopies after being incubated in a $37^{\circ} \mathrm{C}$ with $5 \% \mathrm{CO}_{2}$ incubator for 3 weeks (A) and the colonies were also counted (B). Each bar indicates the mean \pm SD from triplicate assays. The symbol $(*)$ indicates a significant increase as compared with the medium control, while the symbol ( indicates a significant decrease in comparison to p $85 \alpha+/+$ cells $(P<0.05)$. (C-E) the cells as indicated were seeded into 6-well plates. The cells were extracted upon the density reaching $80-90 \%$, and the cell extracts were subjected to Western Blot with indicated antibodies. $\alpha$-Tubulin was used as protein loading controls. $(\mathbf{F}-\mathbf{I})$ the indicated cell transfectants were subjected to soft agar assay in presence of $60 \mathrm{ng} / \mathrm{ml}$ EGF same as described in "A \& B". Each bar indicates the mean \pm SD from triplicate assays. The symbol (*) indicates a significant increase as compared with the medium control, while the symbol (ndicates a significant decrease in comparison to $\mathrm{p} 85 \alpha+/+$ (Nonsense) $(\mathrm{G})$ or p $85 \alpha-/-$ (Vector) $(\mathrm{I})(P<0.05)$. 


\section{Nucleolin (NCL), but not HUR, was responsible for p85a-mediated EGFR mRNA stabilization}

The degradation of mRNAs can be modulated via cisacting sequence elements or trans-acting factors $[29,30]$. Several RNA-binding proteins, such as nucleolin (NCL), HUR, and AUF1, have been reported to bind their target mRNA and modulate mRNA stability [31-33]. Thus, we tested whether those RNA-binding proteins were involved in the p85a upregulation of EGFR mRNA stability. As exhibited in Figure 3A, the downregulation of HUR, NCL and AUF1 protein expression were observed in p $85 \alpha-/-$ cells as compared with those in p $85 \alpha+/+$ cells. Consistently, the mRNA levels of HUR, NCL, and AUF1 were also reduced in p $85 \alpha-1-$ cells (Figure 3B). Given that AUF1 can function as mRNA destabilizers when bound to an ARE-containing mRNA [34], AUF1 was excluded as a p85 $\alpha$ downstream effector being mediating p $85 \alpha$ stabilization of EGFR mRNA. Since HUR has been reported to stabilize its binding mRNA [35], we tested potential role of HUR in $\mathrm{p} 85 \alpha$ regulation of EGFR mRNA stability by introduction of pEGFP-HUR into in p85 $\alpha-/-$ cells. As shown in Figure 3C, the stable transfectants p $85 \alpha^{-1-}$ (GFP-HUR) and its scramble control p85 $\alpha^{-/-}$ (Vector) cells were established and identified. Ectopic expression of GFP-HUR cells dramatically inhibited EGFR mRNA and protein expression in $\mathrm{p} 85 \alpha^{-/-}$(Figure $3 \mathrm{C}$ and $3 \mathrm{D}$ ). Moreover, the results obtained from using specific short hairpin RNAs (shRNAs) targeting HUR to knockdown its expression in p $85 \alpha+/+$ cells, consistently

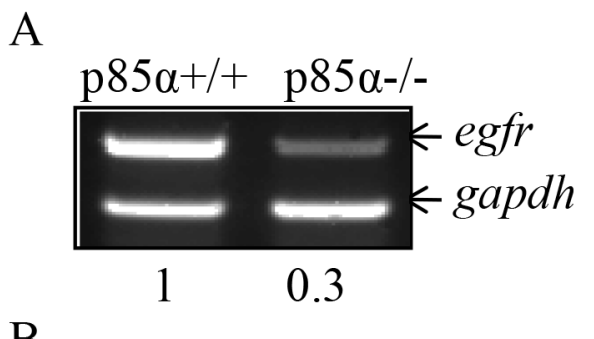

B
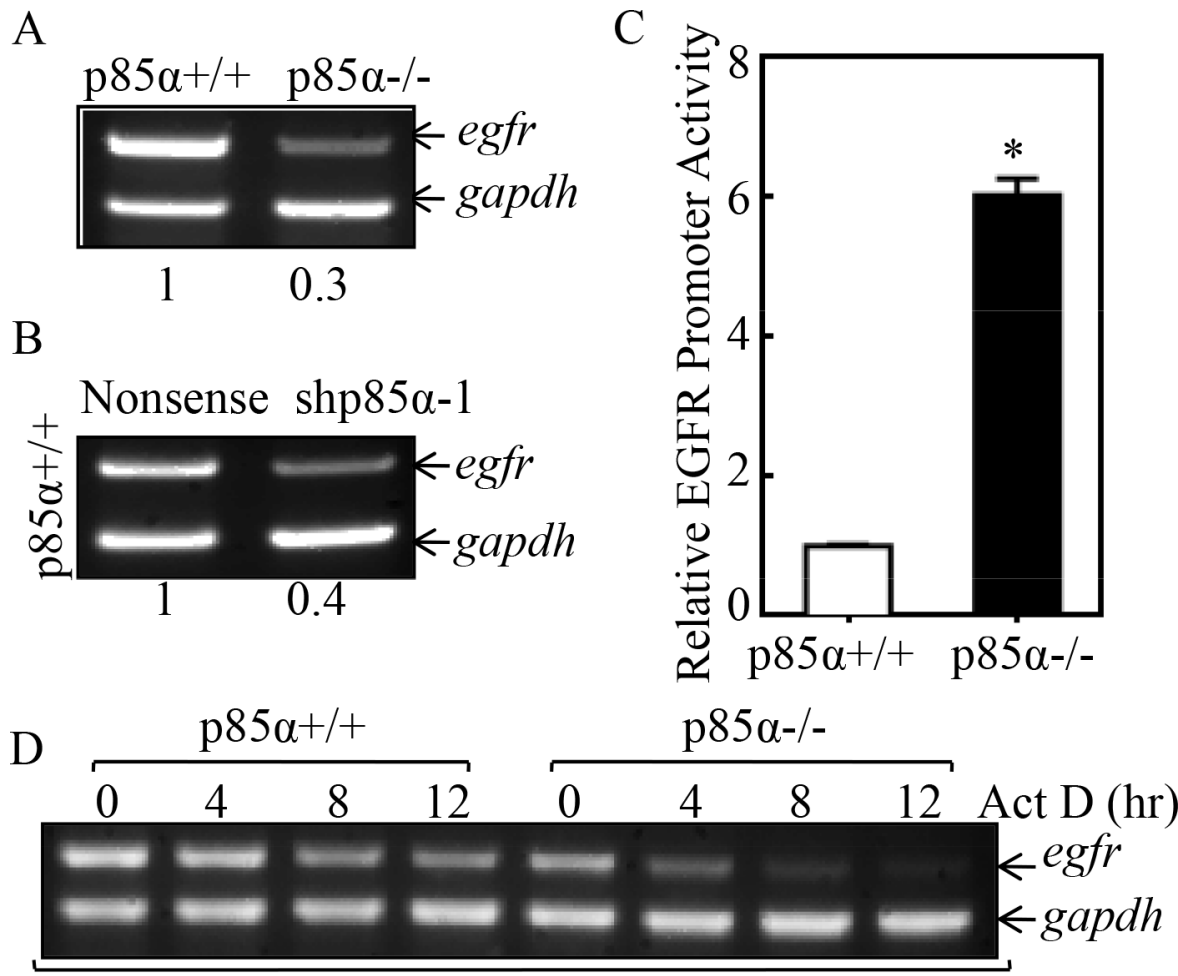

Same cDNA loading in two cells

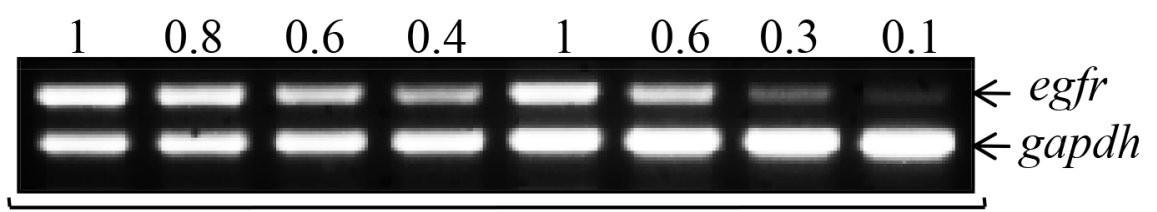

Differential cDNA loading in two cells

Figure 2: p85 $\alpha$ mediated EGFR mRNA stabilization. (A \& B) p85 $\alpha+/+$, p $85 \alpha-/-$ cells and their transfectants, were seeded into 6-well plates. The cells were extracted with Trizol reagent for the total RNA isolation upon the density reaching $80-90 \%$. Egfr mRNA were determined with RT-PCR by using the specific primers. Gapdh was used as an internal control. (C) p $85 \alpha+/+$ and p $85 \alpha-/-$ cells transfected with EGFR promoter-driven luciferase reporter together with pRL-TK were seeded into 96-well plates. After being cultured twenty-four hours, the luciferase activity was measured and pRL-TK was used as an internal control to normalize the transfection efficiency. The results were presented as luciferase activity relative to p $85 \alpha+/+$ cells (Relative EGFR Promoter Activity). Each bar indicates the mean \pm SD of three replicate wells. The symbol $(*)$ indicates a significant increase as compared with p $85 \alpha+/+($ Nonsense $)(P<0.05)$. (D) p85a+/+ and p $85 \alpha-/-$ cells were seeded into 6-well plates. After synchronization, p85a+/+ and p85 $\alpha-/-$ cells were treated with Actinomycin D (Act D) for the indicated time points, then total RNA was isolated and subjected to RT-PCR analysis for mRNA levels of Egfr and Gapdh. 
showed that HUR is a negative regulator, rather than positive regulator, for EGFR mRNA stability (Figure 3E). We, therefore, next investigated the potential role of NCL in regulation of EGFR mRNA stability. The pEGFP-NCL plasmid was stably transfected into p $85 \alpha-/-$ cells and stable transfectants p $85 \alpha-/-$ (GFP-NCL) and its scramble control p $85 \alpha-/-$ (Vector) were identified (Figure 3F). EGFR protein and mRNA expression was markedly increased in p $85 \alpha-/-$ (GFP-NCL) cells as compared with those observed in p $85 \alpha-/-$ (Vector) (Figure 3F and 3G). Moreover, knockdown of nucleolin by its specific shRNAs in $\mathrm{p} 85 \alpha+/+$ cells dramatically reduced EGFR protein and mRNA expression (Figure 3H and 3I). These results reveal that NCL can stabilize EGFR mRNA. To test whether nucleolin is able to bind to EGFR mRNA, RNA-IP assay was carried out in which anti-GFP antibody was used to pull down all mRNAs that physically interacted with GFP-NCL protein. The mRNA was then extracted from the precipitated complex and reverse transcription-PCR was performed to detect the presence of EGFR mRNA. As shown in Figure 3J, EGFR mRNA was found to be specific present in the immune-complex of cell extracts of 293T(GFP-NCL), but not in 293 T (Vector), strongly indicating that nucleolin indeed interacts with EGFR
mRNA. We further compared the egfr mRNA degradation rates between $\mathrm{p} 85 \alpha+/+(\operatorname{shNCL71)}$ and $\mathrm{p} 85 \alpha+/+$ (Nonsense) cells (Figure $3 \mathrm{~K}$ ). To validate the role of nucleolin in stabilizing EGFR mRNA, p85 $\alpha+/+$ (Nonsense) and p85 $\alpha+/+$ (shNCL71) cells were treated with the de novo mRNA synthesis inhibitor actinomycin D (Act D), and the decay rate of EGFR mRNA was assessed by RTPCR. To made the comparable of mRNA levels between p $85 \alpha+/+$ and p $85 \alpha-/-$ cells, we loaded more total cDNA in all samples of $\mathrm{p} 85 \alpha+/+$ (shNCL71) cells for RT-PCR than those in $\mathrm{p} 85 \alpha+/+$ (Nonsense) cells (as seen in gadph in bottom panel of Figure $3 \mathrm{~K}$ ). As shown in Figure $3 \mathrm{~K}$, EGFR mRNA stability was dramatically reduced in p $85 \alpha+/+$ (shNCL71) transfectants in comparison to that in $\mathrm{p} 85 \alpha+/+$ (Nonsense) cells. Our results clearly demonstrate that nucleolin is p $85 \alpha$ downstream mediator being responsible for binding to EGFR mRNA for positive regulation of its stability.

\section{NCL was critical for p85 $\alpha$ promotion of EGF- induced cell transformation}

Our above results showed that NCL could bind to and stabilize EGFR mRNA. Thus, we knocked down
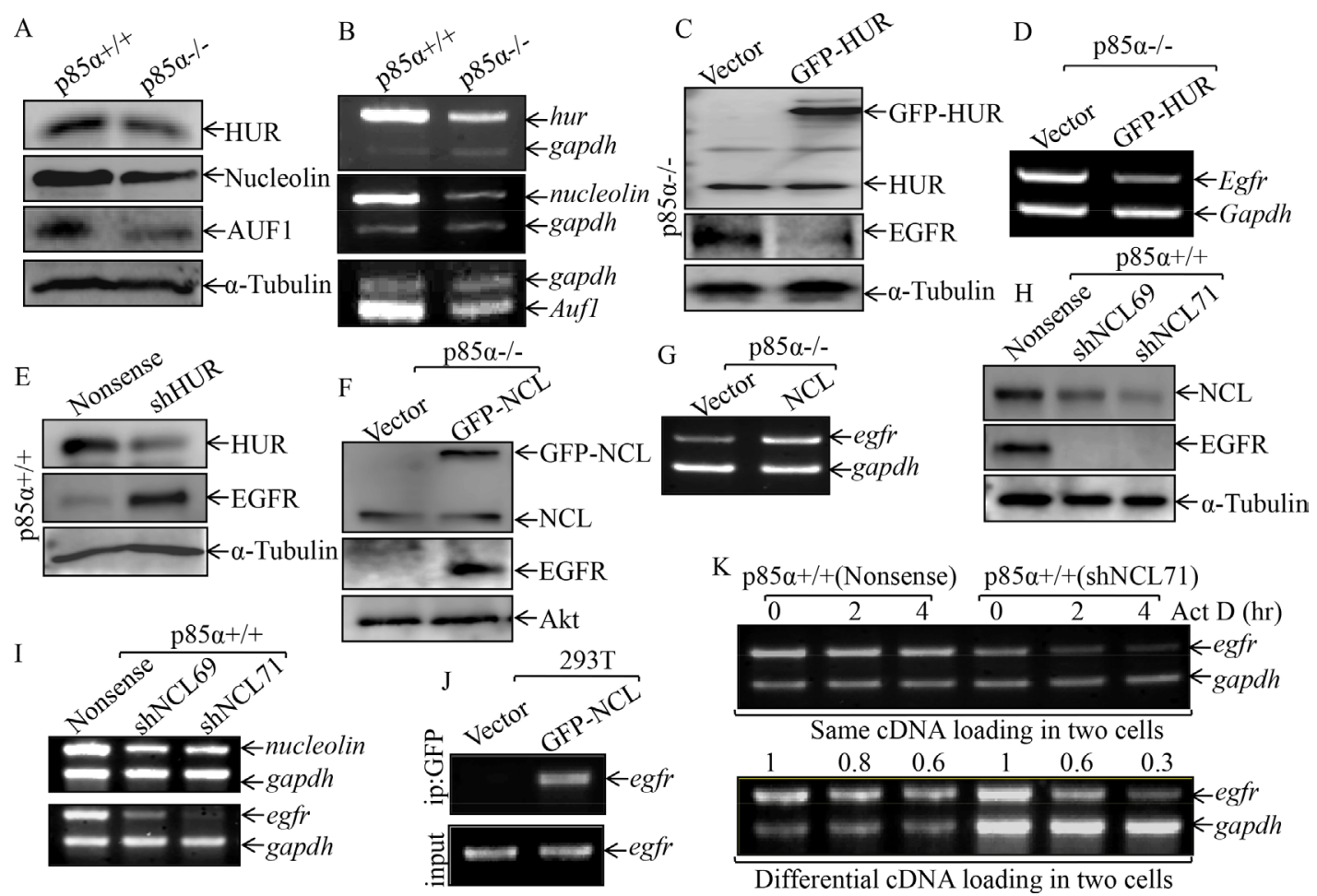

Differential cDNA loading in two cells

Figure 3: NCL, but not HUR, mediated p85 $\alpha$ stabilization of EGFR mRNA. (A \& B) p85 $\alpha+/+$ and p $85 \alpha-/-$ cells, as well as their transfectants, were cultured in 6-well plates till cell density reaching 80-90\%, and then extracted for either whole cell extracts or total RNA. Western blot was carried out for determination of the indicated protein expression with specific antibodies and $\alpha$-Tubulin was used as a control for protein loading $(\mathbf{A}, \mathbf{C}, \mathbf{E}, \mathbf{F} \boldsymbol{\&} \mathbf{H})$; RT-PCR was used to determine indicated mRNA expression and gadph was used as an internal control (B, D, G, \& I). (J) 293T cells were transiently transfected with either GFP-NCL or its control vector. After the cell density reaching $80-90 \%$, the cells were extracted and RNA-IP assay was carried out with specific primer of $e g f r$. (K) the p85a+/+ (Nonsense) or p $85 \alpha+/+$ (shNCL71) were cultured till the cell density reaching 80-90\%, and then treated with Actinomycin D (Act D) for the indicated time points. The total RNA was isolated and subjected to RT-PCR analysis for determination of mRNA levels of Egfr and Gapdh. 
NCL in $p 85 \alpha+/+$ cells to investigate its effects on cell transformation following EGF treatment. As shown in Figure 4A and 4B, knockdown of NCL in p $85 \alpha+/+$ cells, p $85 \alpha$ (shNCL69) and p85 $\alpha+/+$ (shNCL71), dramatically inhibited the malignant cell transformation upon EGF treatment as compared with that in $\mathrm{p} 85 \alpha+/+$ (Nonsense) under same experimental conditions. Moreover, we overexpressed NCL in p $85 \alpha-/-$ cells and the results showed that NCL ectopic overexpression, p85 $\alpha-/-$ (GFP-NCL) cells, restored the malignant cell transformation capability in comparison to that in $\mathrm{p} 85 \alpha-/-$ (Vector) cells following EGF treatment (Figure 4C and 4D). These results demonstrate that nucleolin is critical for p $85 \alpha$ mediation of cell transformation following EGF treatment.

\section{p85a upregulated NCL transcription through c-Jun-dependent axis}

Given our results showing that NCL is important for p $85 \alpha$ regulation of EGFR expression and EGF-induced malignant cell transformation, our subsequent efforts were given to the mechanisms being responsible for $\mathrm{p} 85 \alpha$ upregulation of NCL. NCL expression has been reported to be regulated at multiple levels, including transcription, post-transcription, translation, and post-translation [36]. We, therefore, examined the NCL mRNA expression in p $85 \alpha+/+$ and p $85 \alpha-/-$ cells. The results indicated the NCL mRNA were markedly decreased in p $85 \alpha-/-$ cells in comparison to that in $\mathrm{p} 85 \alpha+/+$ cells (Figure 5A). The results obtained from evaluation of NCL mRNA stability revealed that NCL mRNA degradation rates are only show slightly difference between $\mathrm{p} 85 \alpha+/+$ and $\mathrm{p} 85 \alpha-/-$ cells (Figure 5B), suggesting that $\mathrm{p} 85 \alpha$ might regulate NCL transcription. To test this notion, TFANSFAC ${ }^{\circledR}$ Transcription Factor Binding Sites Software (Biological Database, Wolfenbüttel, Germany) was applied for bioinformatics analysis of the NCL promoter. The results indicated that the mouse NCL gene promoter region contains the putative DNAbinding site of $\mathrm{p} 300$, nuclear factor $\kappa \mathrm{B}(\mathrm{NF}-\kappa \mathrm{B})$, C-Jun, CREB-binding protein (CBP), and E2F1 (Figure 5C). We next determined the role of $\mathrm{p} 85 \alpha$ in regulation of those transcription factor expression and/or nuclear translocation in both $\mathrm{p} 85 \alpha+/+$ and $\mathrm{p} 85 \alpha-/-$ cells. As shown in Figure 5D and 5E, inhibition of p-C-Jun Ser63 and p-C-Jun Ser73 protein expression was observed in the nuclear protein extract of $\mathrm{p} 85 \alpha-/-$ cells, while there was no markedly inhibition of NF-кB (p65), C-Jun and CREB. Given that E2F1 and p300 both can promote the transcription of target gene $[37,38]$ and they increased in $p 85 \alpha-/-$ cells,
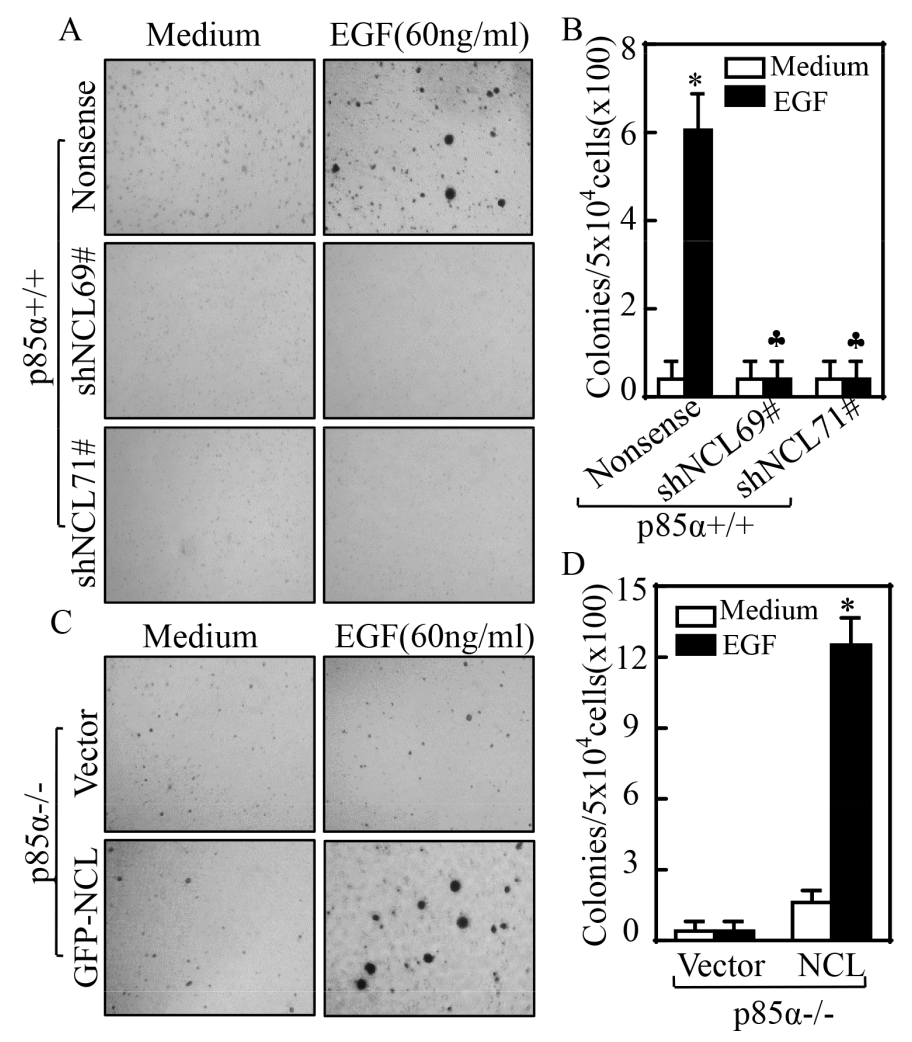

Figure 4: NCL is critical for p85a-regulated EGF-induced malignant cell transformation. $5 \times 10^{4}$ of stable transfectants of p $85 \alpha+/+$ and p $85 \alpha^{-1-}$ as indicated were subjected to soft agar assay in presence of $60 \mathrm{ng} / \mathrm{ml}$ EGF. The images were captured under inverted microscopies after being incubated in a $37^{\circ} \mathrm{C}$ with $5 \% \mathrm{CO}_{2}$ incubator for 3 weeks $(\mathbf{A} \& \mathbf{C})$ and the colonies were counted (B \& D). Each bar indicates the mean $\pm \mathrm{SD}$ from triplicate assays. (B) The symbol $(*)$ indicates a significant increase as compared with the medium control, while the symbol $(*)$ indicates a significant decrease in comparison to p85a+/+ (Nonsense) cells $(P<0.05)$. The symbol $(*)$ indicates a significant increase as compared with p85 $\alpha-1-$ (Vector) $(P<0.05)(\mathrm{D})$. 
E2F1 and p300 were excluded as a p85 $\alpha$ downstream effector being mediating the transcription of nucleolin. To define the role of C-Jun in p85 $\alpha$-mediated nucleolin transcription, we co-transfected nucleolin promoter-driven luciferase reporter with C-Jun into p $85 \alpha-/-$ cells and the effect of C-Jun overexpression on nucleolin transcription was evaluated. The results showed that ectopic expression of C-Jun resulted in increasing of nucleolin promoter transcriptional activity (Figure 6A). Consistently, protein and mRNA expression of Nucleolin and EGFR was also profoundly upregulated in p $85 \alpha-/-$ cells (Figure 6B \& 6C). Moreover, overexpression of C-Jun also significantly rescued malignant cell transformation ability of $\mathrm{p} 85 \alpha-/-$ cells following EGF treatment (Figure 6D \& 6E). Our results conclusively demonstrate that C-Jun mediates nucleolin transcription and expression, which subsequently upregulating EGFR mRNA stability, and in turn promoting EGF-induced malignant cell transformation as summarized in Figure 6F.

\section{DISCUSSION}

Although the deregulation of phosphatidylinositol 3-kinase $(\mathrm{PI} 3 \mathrm{~K})$ and its regulatory unit $\mathrm{p} 85 \alpha$ has been reported in many human cancers $[39,40]$, the mechanisms for their action in cancer development are far away from understood. EGFR is overexpressed in many aggressive cancers, and previous study indicates that $\mathrm{p} 85 \alpha$ can be activated by transmembrane tyrosine kinase receptors, such as EGFR, HER2 and IGF1-R [41]. However, the role of $p 85 \alpha$ in regulation of EGFR expression has never been elucidated. Here we found that $\mathrm{p} 85 \alpha$ has a positive regulatory effect on EGFR expression, and this positive effect of $p 85 \alpha$ is regulated by NCL-dependent increased EGFR mRNA stability and EGFR protein expression. Further studies found that $\mathrm{p} 85 \alpha$ is crucial for C-Juninitiated NCL transcription, which can bind to EGFR mRNA and inhibit its mRNA degradation, by which $p 85 \alpha$ promote malignant cell transformation following EGF
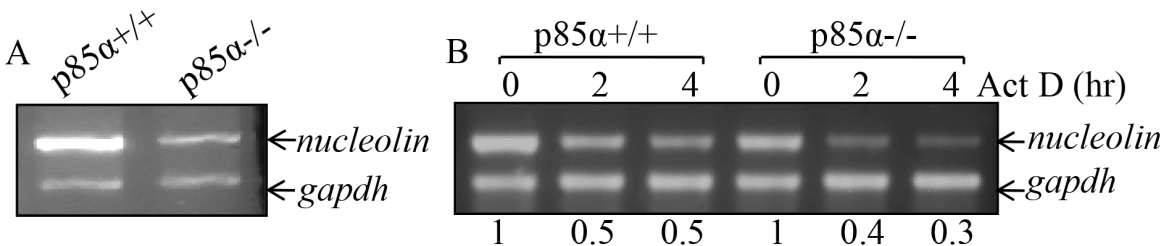

C

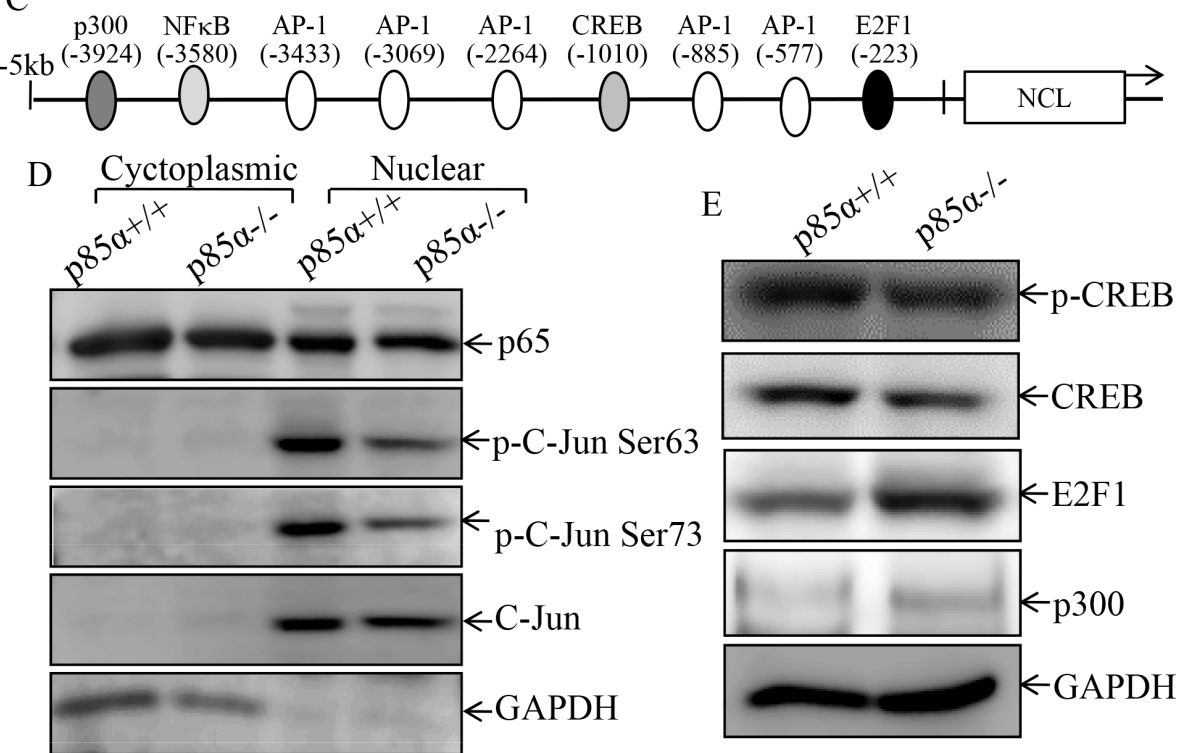

Figure 5: p85 $\alpha$ regulated NCL transcription and C-Jun activation. (A) p $85 \alpha+/+$ and p $85 \alpha-/-$ cells were cultured in 6 -well plates till cell density reaching $80-90 \%$, and then extracted for total RNA with Trizol reagent. RT-PCR was used to determine nucleolin mRNA expression, while gadph was used as an internal control, (B) p85a+/+ and p85 $\alpha-1-$ cells were cultured in 6-well plates till cell density reaching $80-90 \%$, and the cells were then treated with Act D for the indicated time points, and were then used for total RNA isolation. The total RNA was subjected to RT-PCR for determination of mRNA levels of Egfr and Gapdh. (C) Potential transcriptional factor binding sites in NCL promoter region $(-5000-+1)$ analyzed by using the TRANSFAC 8.3 engine online. (D) $p 85 \alpha+/+$ and $p 85 \alpha-/-$ cells were cultured in 6-well plates till cell density reaching 80-90\%, the cells were extracted and the whole cell extracts were used to isolate cytoplasmic and nuclear fractions according to the protocol of the nuclear/cytosol fractionation kit. The isolated protein fractions were subjected to Western blot. GAPDH were used as control for protein loading. (E) p $85 \alpha+/+$ and p85 $\alpha-/-$ cells were cultured in 6 -well plates till cell density reaching $80-90 \%$, the cells were extracted and cell extracts were subjected to Western blot for determination of the indicated protein expression with specific antibodies and GAPDH was used as protein loading controls. 
treatment. Our findings that $\mathrm{p} 85 \alpha$ regulates EGFR mRNA stability and cell transformation via initiating C-Jun/ nucleolin axis provide a new insight into the understanding of natural face of $\mathrm{p} 85 \alpha$ in regulation of multiple cellular function.

The epidermal growth factor receptor (EGFR) was discovered by Stanley Cohen, and is a member cell-surface receptor of the ErbB family, a subfamily of four closely related receptor tyrosine kinases, including EGFR (ErbB-1), HER2/c-neu (ErbB-2), Her 3 (ErbB-3) and Her 4 (ErbB-4) [42-45]. EGFR exists on the cell surface and is activated by binding of its specific ligands, including epidermal growth factor and transforming growth factor $\alpha(\mathrm{TGF} \alpha)$. Upon activation by its growth factor ligands, EGFR undergoes a transition from an inactive monomeric form to an active homodimer [46]. In addition to forming homodimers after ligand binding, EGFR may pair with another member of the ErbB receptor family, such as ErbB2/Her2/neu, to create an activated heterodimer [47]. EGFR dimerization stimulates its intrinsic intracellular protein-tyrosine kinase activity. As a result, autophosphorylation of several tyrosine $(\mathrm{Y})$ residues in the $\mathrm{C}$-terminal domain of EGFR occurs [48]. This autophosphorylation elicits downstream activation and signaling by several other proteins that associate with the phosphorylated tyrosines through their own phosphotyrosine-binding SH2 domains. These downstream signaling proteins initiate several signal transduction cascades, such as MAPK, Akt and JNK pathways, leading to a serial gene expression, by which mediates alteration of cellular function, such as cell migration, adhesion, proliferation and transformation. It has been reported that mutations leading to EGFR constant activation could also produce uncontrolled cell division [49]. The somatic mutations leading to EGFR overexpression or over-activated have been associated with a number of cancer development, progression, angiogenesis and metastatic spread [50-52]. Dysregulation and/or amplification of the EGFR gene and/or mutations in the EGFR tyrosine kinase domain are known to be implicated in about $30 \%$ of all epithelial cancers [8-11]. Thus, the EGFR is becoming a dominant target for scientists attempting to understand cancer and for clinicians attempting to improve cancer treatment,

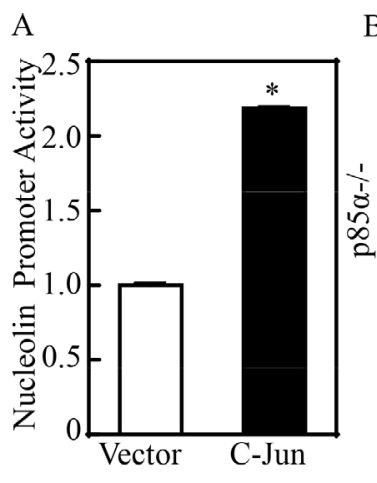

B
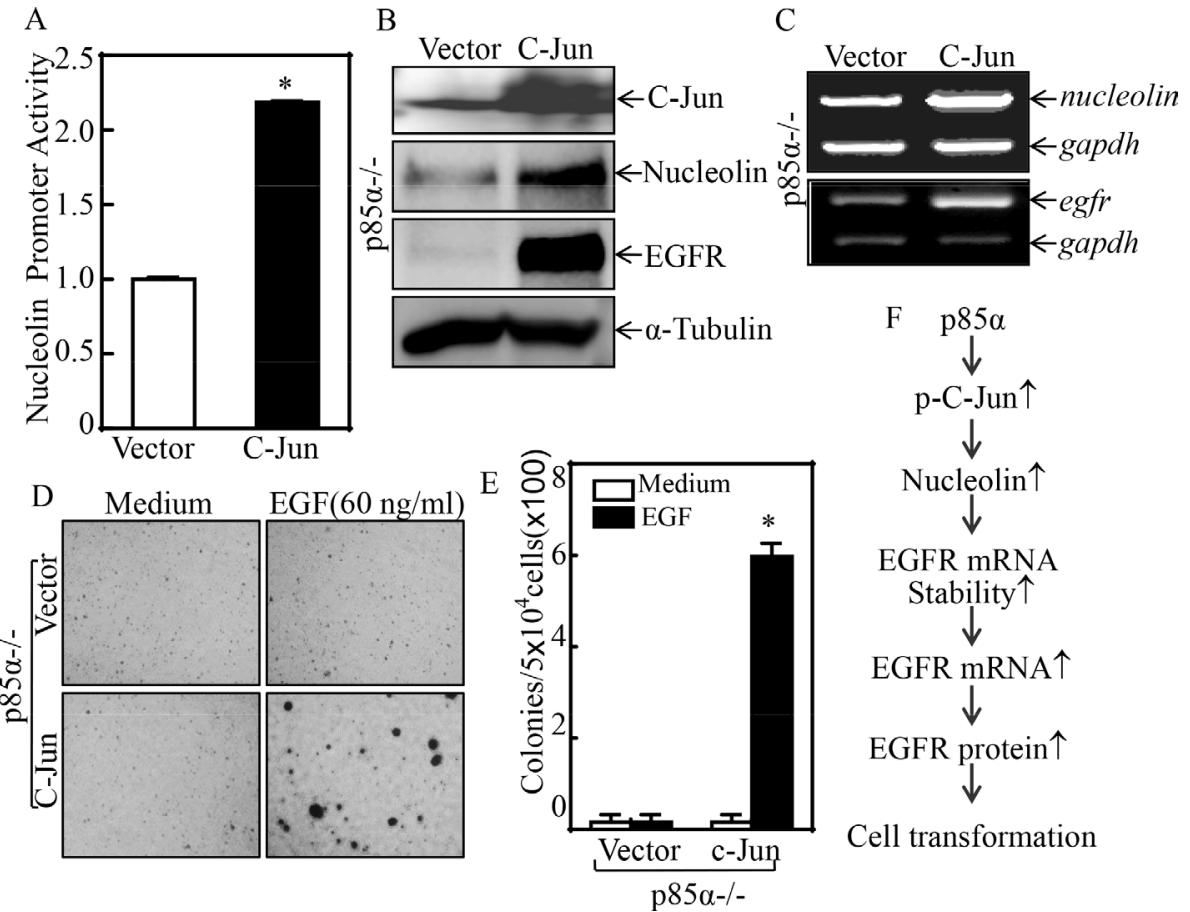

Cell transformation

Figure 6: C-Jun mediated nucleolin transcription and EGF-induced cell transformation. (A) p $85 \alpha-/-$ (Vector) and p $85 \alpha-/-$ (C-Jun) were transfected with nucleolin promoter-driven luciferase reporter together with pRL-TK. The transfectants were seeded into 96-well plates for determination of nucleolin promoter activity by measuring luciferase activity. pRL-TK was used as an internal control to normalize the transfection efficiency. Each bar indicates the mean \pm SD from three replicate assays. (B \& C) p85 $\alpha-/-($ Vector) and p $85 \alpha-/-$ (C-Jun) were extracted for either whole cell protein extracts or total RNA. Whole cell extracts were subjected to Western blot for determination of the indicated protein expression with specific antibodies and $\alpha$-Tubulin was used as protein loading controls (B). Total RNA was subjected to RT-PCR for determination the indicated mRNA expression, and gadph was used as an internal control (C). (D \& E)

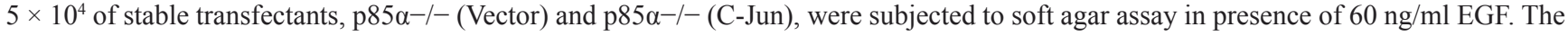
images were captured under inverted microscopies after being incubated in a $37^{\circ} \mathrm{C}$ with $5 \% \mathrm{CO}_{2}$ incubator for 3 weeks (D) and the colonies were also counted (E). Each bar indicates the mean \pm SD from triplicate assays. The symbol $(*)$ indicates a significant increase as compared with p85 $\alpha-/-$ (Vector) $(P<0.05)$. (F), Novel molecular mechanism underlying p85 $\alpha$ regulation of EGFR expression and malignant cell transformation followed EGF treatment. 
including using specific tyrosine kinase inhibitors (TKI) and monoclonal antibodies specific targeting EGFR. However, many patients develop resistance to those therapeutic drugs. Therefore, investigating and understanding of the EGFR upstream modulatory mechanisms might provide some novel targets for cancer therapy. p85 $\alpha$ is a multifunctional protein and serves as a critical mediator in various physiological processes, via either PI3K-dependent or -independent mechanisms $[25,53,54]$. One previous study reports the involvement of p85 $\alpha$ in the p53-mediated apoptotic response to oxidative stress, which is unrelated to the activation of the PI3K signal transduction pathway, suggesting the potential role of p85 $\alpha$ in transmitting cell damage signaling [55], while our published studies also demonstrate that p $85 \alpha$ plays a critical role in mediating UV-induced apoptosis through the induction of TNF $\alpha$ gene expression and this special pro-apoptotic effect of $\mathrm{p} 85 \alpha$ is unrelated to the PI3Kdependent signaling pathway [26]. We further demonstrate that the inducible transcription factor NFAT3 is the major downstream target of $\mathrm{p} 85 \alpha$ for mediating UV-induced $\mathrm{TNF} \alpha$ transcription [26]. Our current study found that EGFR can be regulated by $\mathrm{p} 85 \alpha$ through C-Jun-mediated transcriptional activation of nucleolin, which could bind to and stabilize EGFR mRNA and subsequently resulted in EGFR protein expression, and further in turn promoting cell transformation following EGF treatment. This novel finding of new function of $\mathrm{p} 85 \alpha$ and its regulated nucleolin could potential serve as new targets for cancer prevention and therapy.

Nucleolin (NCL), a ubiquitously expressed acidic phosphoprotein with key functions both in transcription and in the synthesis and maturation of ribosomes [56]. NCL was originally identified as a nuclear protein localizing primarily to the nucleoli, but is now appreciated to undergo nuclear-cytoplasmic shuttling and to also be present on the cell surface of some types of cells [57, 58]. NCL has been found to bind to the mRNA of several important genes, including p53 [59], bcl-2 [60], and bcl-xl [61], leading to regulation on mRNA turnover or translation, NCL is therefore involved in critical aspects of gene expression regulation, by which modulates cell proliferation, cell growth and many other cellular function as well $[62,63]$. Inhibition of cell-surface NCL and NCL activities suppresses cell and tumor growth in breast, prostate, and glioma cell lines [64]. An aptamer-targeting NCL, AS1411, is in phase II clinical trial for relapsed/ refractory acute myeloid leukemia [65], metastatic renal cell carcinoma [66] and malignant melanoma [67]. Previous study has demonstrated that NCL can bind EGFR protein to enhance EGFR activation [68]. Here we found that $\mathrm{p} 85 \alpha$ upregulated NCL expression, and the upregulated-NCL consequently mediated EGFR expression and EGF-induced cellular malignant transformation. Regulation of mRNA stabilization is one of the major mechanisms responsible for cells controlling protein expression and is regulated by multiple proteins
$[15,16]$. The defect in regulation of mRNA stability might lead to complicated disorders, including cancers [18]. Rates of mRNA degradation in the cytoplasm are regulated by the sequences of the nucleic acid (ciselements on the mRNA) and the proteins that bind to them (trans-acting factors) [69]. The most well-characterized mRNA cis-elements are AU-rich sequences [70]. There are distinct classes of AU-rich elements (AREs), ranging from arrays composed of several AUUUA elements in oncogene mRNAs to individual AUUUA elements scattered in 3'-UTR sequences of EGFR mRNAs [71, 72]. Our studies here revealed that $\mathrm{p} 85 \alpha$-upregulated $\mathrm{NCL}$ can bind to EGFR mRNA and subsequently elevating EGFR mRNA stability, further facilitating EGF-induced cellular malignant transformation, as well as cell migration (Supplementary Figure 1). During our studies, we also found that NCL is regulated by $\mathrm{p} 85 \alpha$ at transcription level, rather than mRNA degradation level. Although Bioinformatics analysis indicated that there are a series of the putative transcription factor binding sites, including specificity protein (Sp)-1, CREB, E2F and AP-1 in the promoter regions of the NCL. The results obtained from comprehensive investigations demonstrated that AP-1 (C-Jun) was crucial for p85 $\alpha$-initiated nucleolin transcription, and its downstream biological effects.

In summary, our current studies revealed a novel link between p85 $\alpha$ and EGFR mRNA stability and EGFR upregulation through p $85 \alpha$-initiated and C-Jun-mediated nucleolin transcriptional activation. The newly identified NCL directly binding to and interacting with EGFR mRNA and stabilizing EGFR mRNA and its expression is further responsible for promotion of EGF-induced malignant cell transformation and migration. These $\mathrm{p} 85 \alpha-$ related new findings provide an insight into understanding of the new face of p85 $\alpha$ in tumorigenesis, suggesting that p $85 \alpha$ could potentially be used as a preventive/therapeutic target for cancers.

\section{MATERIALS AND METHODS}

\section{Reagents, antibodies and plasmids}

Actinomycin D (Act D) and EGF were purchased from Calbiochem (San Diego, CA) and Promega (San Luis Obispo, CA, USA), respectively. The dual luciferase assay kit was obtained from Promega (Madison, WI, USA). TRIzol reagent and SuperScriptTM First-Strand Synthesis system were bought from Invitrogen (Grand Island, NY, USA). PolyJetTM DNA In vitro Transfection Reagent was purchased from SignaGen Laboratories (Rockville, MD, USA). The specific antibody for $\mathrm{p} 85 \alpha$ was purchased from Abcam (Cambridge, MA, USA). NCL, HUR, $\alpha$-Tubulin, p300 and E2F1 antibodies were purchased from Santa Cruz Biotechnology, Inc. (Santa Cruz, CA, USA), EGFR, C-Jun, p65, CREB and p-CREB antibodies were purchased from Cell Signaling Technology (Beverly, MA, USA), AUF1 antibody was 
purchased from Aviva (San Diego, CA, USA). GAPDH antibody was purchased from Gene Tex (Irvine, CA, USA). The EGFR promoter-luciferase reporter, in which the transcription of the luciferase reporter gene is driven by the up-stream 5'-flanking region of the EGFR, and NCL promoter-Luciferase reporter (nucleotides - 1260 to +60 ), had been described previously [73]. EGFR-GFP was obtained from Addgene (plasmid 32751). GFP-NCL expression vector was a generous gift from Dr. Michael B. Kastan (Duke University School of Medicine, Duke Cancer Institute, Durham, NC) [59]. GFP-HUR expression vector was a generous gift from Dr. Imed-Eddine Gallouzi (McGill University Health Center, McGill University, Montreal, Canada) [74]. The plasmid of C-Jun was used and is described in our previous study [75]. The shRNAs specific targeting $\mathrm{p} 85 \alpha$, HUR, and NCL, were bought from Open Biosystems (Huntsville, AL, USA).

\section{Cell culture and transfection}

p $85 \alpha+/+$ and p $85 \alpha-/-$ cells were isolated from wildtype and $\mathrm{p} 85 \alpha-/-$ mice and described in a previous study [26]. The cells were maintained in DMEM (Invitrogen, Carlsbad, CA, USA) supplemented with 10\% FBS (Nova-Tech, Grand Island, NE, USA), 1\% penicillin/ streptomycin, and $2 \mathrm{mM}$ L-glutamine (Life Technologies, Grand Island, $\mathrm{NY}, \mathrm{USA}$ ) at $37^{\circ} \mathrm{C}$ in $5 \% \mathrm{CO}_{2}$ incubator. Cell transfections were performed by using PolyJetTM DNA In vitro Transfection Reagent, according to the manufacturer's instruction. The stable transfectants of shp85 $\alpha$, shHUR, shNCL in p $85 \alpha+/+$ cells were selected in culture medium containing $5 \mu \mathrm{g} / \mathrm{mL}$ puromycin (Alexis, Plymouth, PA) and the resultant stable transfectants were identified for desired protein expression. And the stable transfectants of EGFR, HUR, NCL, C-Jun in p $85 \alpha-/-$ cells were selected by $2.5 \mu \mathrm{g} / \mathrm{ml}$ blasticidin (Fisher Scientific, Pittsburgh, PA).

\section{Luciferase reporter assay}

MEF cells were co-transfected with the EGFR- or NCL promoter-luciferase reporter constructs, together with the Renilla luciferase vector pRL-TK (Promega, Madison, WI). After stabilization, the cells were treated with passive lysis buffer according to the dual-luciferase assay manual (Promega), and then measured with a luminometer (Lumat LB9507, Berthold Tech., Bad Wildbad, Germany). The firefly luciferase signal was normalized to the Renilla luciferase signal for each individual analysis to eliminate the variations of transfection efficiencies as previously described [73].

\section{Soft agar colony formation assay}

Soft agar assay was performed according to the protocol described previously [76]. Briefly, the cells were suspended in $1 \mathrm{ml}$ of medium containing $0.33 \%$ agar and applied onto $3 \mathrm{ml}$ of pre-solidified $0.6 \%$ agar plus $10 \%$ FBS in 6 -well plates $\left(1 \times 10^{4}\right.$ cells/well $)$ with or without EGF $(60 \mathrm{ng} / \mathrm{ml})$. After about 3 weeks of incubation, colonies were observed under a phase contrast microscope, photographed and counted. The results were expressed as the mean \pm S.D. of triplicate experiments.

\section{Reverse transcription-PCR (RT-PCR)}

Total RNA was extracted with Trizol reagent. $5 \mu \mathrm{g}$ total RNA was used for first-strand cDNA synthesis with oligdT primer by SuperScriptTM First-Strand Synthesis system (Invitrogen). Specific primer pairs were designed for amplifying murine HUR (forward: 5'-AAG AGG CAA TTA CCA GTT TCA-3', backward: 5'-CTT CAT AGT TTG TCA TGG TCA C-3'), EGFR (forward: 5'-GAG AGG AGA ACT GCC AGA A-3', backward: 5'-GTA GCA TTT ATG GAG AGT G-3'), NCL (forward: 5'-GGA GGT TGT CAT CCC TCA GA-3', backward: 5'-TCC TCC TCA GCC ACA CTC TT-3'), GAPDH (forward: 5'-TGC AGT GGC AAA GTG GAG ATT-3', backward: 5'-TTT TGG CTC CAC CCT TCA AGT-3'). The PCR products were separated onto $3 \%$ agarose gels, stained with ethidium bromide (EB), and the images scanned with a UV light as described previously [77].

\section{Immunoblotting assay}

Whole-cells were washed with ice-cold PBS, and then extracted with cell lysis buffer $(10 \mathrm{mM}$ Tris- $\mathrm{HCl}$, $\mathrm{pH} 7.4,1 \% \mathrm{SDS}, 1 \mathrm{mM} \mathrm{Na}_{3} \mathrm{VO}_{4}$, and proteasome inhibitor). Cytoplasmic and nuclear proteins were prepared with the Nuclear/Cytosol Fractionation Kit (BioVision, Mountain View, CA, USA) following the manufacturer's protocols. The cell extracts were subjected to Western blotting with each of the antibodies. The protein bands specifically bound to the primary antibodies were detected using an alkaline phosphatase-linked secondary antibody and ECF (enhanced chemifluorescence) western blotting analysis system (Amersham Pharmacia Biotech, Piscataway, NJ) as previously described [78]. The results shown were representative of at least three independent experiments.

\section{RNA-IP assay}

RNA-IP assay was performed as described previously [79]. Briefly, 293T cells were cultured in $10-\mathrm{cm}$ dishes. When cell confluence reached $70 \sim 80 \%$, cells were transiently transfected with GFP-NCL and its GFP vector control. Twenty four hours after the transfection, the cells were extracted by using polysomelysis buffer (10 mM HEPES pH 7; $100 \mathrm{mM} \mathrm{KCl;} 5 \mathrm{mM} \mathrm{MgCl2}$; 25 mM EDTA; 0.5\% IGEPAL; 2 mM DTT; 50 units $/ \mathrm{ml}$ RNase OUT; 50 units/ml Superase IN; $0.2 \mathrm{mg} / \mathrm{ml}$ heparin; and complete proteinase inhibitor). The cell lysates were centrifuged at $14,000 \times \mathrm{g}$ for $10 \mathrm{~min}$ at $4{ }^{\circ} \mathrm{C}$. The anti-GFP agarose beads A/G (Vector laboratories, 
Burlingame, CA, USA ) were added into the supernatant and rotated overnight at $4{ }^{\circ} \mathrm{C}$ in NET2 buffer (50 mM Tris$\mathrm{HCl}, \mathrm{pH} 7.4,150 \mathrm{mM}$ sodium chloride, $1 \mathrm{mM}$ magnesium chloride, $0.05 \%$ IGEPAL, $50 \mathrm{U} / \mathrm{mL}$ RNase OUT, $50 \mathrm{U} / \mathrm{mL}$ Superase IN, $1 \mathrm{mM}$ dithiothreitol, and $30 \mathrm{mM}$ EDTA). The beads were washed three times, and resuspended in $100 \mu \mathrm{L}$ NET2 and $100 \mu \mathrm{L}$ SDS-TE $(20 \mathrm{mM}$ Tris- $\mathrm{HCl}$, $\mathrm{pH} 7.5,2$ mM EDTA, and 2\% sodium dodecyl sulfate) and then incubated at $55^{\circ} \mathrm{C}$ for $30 \mathrm{~min}$, mixing occasionally. The RNAs in the buffer of the beads were extracted by phenol-chloroform-isoamyl alcohol and RT-PCR was performed to identify the mRNA presented in the immunecomplex.

\section{Statistical analysis}

The student's $t$-test was used to determine the significance between treated and untreated group. The results are expressed as mean \pm SD from at least three independent experiments. $P<0.05$ was considered as a significant difference between compared groups.

\section{ACKNOWLEDGMENTS AND FUNDING}

We thank Dr. Michael B. Kastan from Duke Cancer Institute for providing us with GFP-NCL expression vector. This work was partially supported by the grants of NIH/NCI CA112557, CA165980 and CA177665, and NIH/NIEHS ES000260; the Natural Science Foundation of China (NSFC81229002, NSFC81372946), Key Project of Science and Technology Innovation Team of Zhejiang Province (2013TD10).

\section{CONFLICTS OF INTEREST}

No potential conflicts of interest were disclosed.

\section{REFERENCES}

1. Alroy I, Yarden Y. The ErbB signaling network in embryogenesis and oncogenesis: signal diversification through combinatorial ligand-receptor interactions. FEBS Lett. 1997; 410:83-86.

2. Prigent SA, Lemoine NR. The type 1 (EGFR-related) family of growth factor receptors and their ligands. Prog Growth Factor Res. 1992; 4:1-24.

3. Shing Y, Christofori G, Hanahan D, Ono Y, Sasada R, Igarashi K, Folkman J. Betacellulin: a mitogen from pancreatic beta cell tumors. Science. 1993; 259:1604-1607.

4. Toyoda H, Komurasaki T, Uchida D, Takayama Y, Isobe T, Okuyama T, Hanada K. Epiregulin a novel epidermal growth factor with mitogenic activity for rat primary hepatocytes. J Biol Chem. 1995; 270:7495-7500.

5. Pawson T, Gish GD. SH2 and SH3 domains: from structure to function. Cell. 1992; 71:359-362.
6. Yarden Y. The EGFR family and its ligands in human cancer: signalling mechanisms and therapeutic opportunities. Eur J Cancer. 2001; 37:3-8.

7. Gschwind A, Zwick E, Prenzel N, Leserer M, Ullrich A. Cell communication networks: epidermal growth factor receptor transactivation as the paradigm for interreceptor signal transmission. Oncogene. 2001; 20:1594-1600.

8. Hirsch F, Varella-Garcia M, Cappuzzo F. Predictive value of EGFR and HER2 overexpression in advanced non-smallcell lung cancer. Oncogene. 2009; 28:S32-S37.

9. Bhargava R, Gerald WL, Li AR, Pan Q, Lal P, Ladanyi M, Chen B. EGFR gene amplification in breast cancer: correlation with epidermal growth factor receptor mRNA and protein expression and HER-2 status and absence of EGFRactivating mutations. Modern Pathol. 2005; 18:1027-1033.

10. Spano J-P, Lagorce C, Atlan D, Milano G, Domont J, Benamouzig R, Attar A, Benichou J, Martin A, Morere J-F. Impact of EGFR expression on colorectal cancer patient prognosis and survival. Ann Oncol. 2005; 16:102-108.

11. Kim M, Lee H, Lee H, Jeon Y, Yang H, Kim W. EGFR in gastric carcinomas: prognostic significance of protein overexpression and high gene copy number. Histopathology. 2008; 52:738-746.

12. Scaltriti M, Baselga J. The epidermal growth factor receptor pathway: a model for targeted therapy. Clin Cancer Res. 2006; 12:5268-5272.

13. Roskoski R. The ErbB/HER receptor protein-tyrosine kinases and cancer. Biochem Biophys Res Commun. 2004; 319:1-11.

14. de-Leon SB-T, Davidson EH. Modeling the dynamics of transcriptional gene regulatory networks for animal development. Dev Biol. 2009; 325:317-328.

15. Lal A, Mazan-Mamczarz K, Kawai T, Yang X, Martindale JL, Gorospe M. Concurrent versus individual binding of HuR and AUF1 to common labile target mRNAs. EMBO J. 2004; 23:3092-3102.

16. Marderosian M, Sharma A, Funk A, Vartanian R, Masri J, Jo O, Gera J. Tristetraprolin regulates Cyclin D1 and c-Myc mRNA stability in response to rapamycin in an Aktdependent manner via p38 MAPK signaling. Oncogene. 2006; 25:6277-6290.

17. Wang D, Su L, Huang D, Zhang H, Shin DM, Chen ZG. Downregulation of E-Cadherin enhances proliferation of head and neck cancer through transcriptional regulation of EGFR. Mol Cancer. 2011; 10:116.

18. Benjamin D, Moroni C. mRNA stability and cancer: an emerging link? Expert Opin Biol Th.2007; 10:1515-1529. 2007.

19. Garneau NL, Wilusz J, Wilusz CJ. The highways and byways of mRNA decay. Nat Rev Mol Cell Biol. 2007; 8:113-126.

20. Franke TF, Hornik CP, Segev L, Shostak GA, Sugimoto C. PI3K/Akt and apoptosis: size matters. Oncogene. 2003; 22:8983-8998. 
21. Samuels Y, Ericson K. Oncogenic PI3K and its role in cancer. Curr Opin Oncol. 2006; 18:77-82.

22. Fruman DA, Meyers RE, Cantley LC. Phosphoinositide kinases. Annu Rev Biochem. 1998; 67:481-507.

23. Falvo JV, Uglialoro AM, Brinkman BM, Merika M, Parekh BS, Tsai EY, King HC, Morielli AD, Peralta EG, Maniatis T. Stimulus-specific assembly of enhancer complexes on the tumor necrosis factor alpha gene promoter. Mol Cell Biol. 2000; 20:2239-2247.

24. Ueki K, Fruman DA, Brachmann SM, Tseng Y-H, Cantley LC, Kahn CR. Molecular balance between the regulatory and catalytic subunits of phosphoinositide 3-kinase regulates cell signaling and survival. Mol Cell Biol. 2002; 22:965-977.

25. Luo J, Field SJ, Lee JY, Engelman JA, Cantley LC. The p85 regulatory subunit of phosphoinositide 3-kinase downregulates IRS-1 signaling via the formation of a sequestration complex. J Cell Biol. 2005; 170:455-464.

26. Song L, Li J, Ye J, Yu G, Ding J, Zhang D, Ouyang W, Dong Z, Kim SO, Huang C. p85 $\alpha$ acts as a novel signal transducer for mediation of cellular apoptotic response to UV radiation. Mol Cell Biol. 2007; 27:2713-2731.

27. Hunter T, Karin M. The regulation of transcription by phosphorylation. Cell. 1992; 70:375-387.

28. Franovic A, Gunaratnam L, Smith K, Robert I, Patten D, Lee S. Translational up-regulation of the EGFR by tumor hypoxia provides a nonmutational explanation for its overexpression in human cancer. Proc Natl Acad Sci U S A. 2007; 104:13092-13097.

29. Kramer S, Carrington M. Trans-acting proteins regulating mRNA maturation, stability and translation in trypanosomatids. Trends Parasitol. 2011; 27:23-30.

30. Lasa M, Mahtani KR, Finch A, Brewer G, Saklatvala J, Clark AR. Regulation of cyclooxygenase 2 mRNA stability by the mitogen-activated protein kinase p38 signaling cascade. Mol Cell Biol. 2000; 20:4265-4274.

31. Abdelmohsen K, Gorospe M. Posttranscriptional regulation of cancer traits by HuR. Wiley Interdiscip Rev RNA. 2010; $1: 214-229$.

32. Audic Y, Hartley RS. Post-transcriptional regulation in cancer. Nat Cell Biol. 2004; 96:479-498.

33. White EJ, Brewer G, Wilson GM. Post-transcriptional control of gene expression by AUF1: mechanisms, physiological targets, and regulation. BBA Gene Regul Mech. 2013; 1829:680-688.

34. Lai WS, Carballo E, Strum JR, Kennington EA, Phillips RS, Blackshear PJ. Evidence that tristetraprolin binds to AU-rich elements and promotes the deadenylation and destabilization of tumor necrosis factor alpha mRNA. Mol Cell Biol. 1999; 19:4311-4323.

35. Fan XC, Steitz JA. Overexpression of HuR, a nuclearcytoplasmic shuttling protein, increases the in vivo stability of ARE-containing mRNAs. EMBO J. 1998; 17:3448-3460.
36. Bicknell K, Brooks G, Kaiser P, Chen H, Dove BK, Hiscox JA Nucleolin is regulated both at the level of transcription and translation. Biochem Biophys Res Commun. 2005; 332:817-822.

37. Polager S, Ginsberg D. E2F-at the crossroads of life and death. Trends Cell Biol. 2008; 18:528-535.

38. Kasper LH, Fukuyama T, Biesen MA, Boussouar F, Tong C, De Pauw A, Murray PJ, Van Deursen JM, Brindle PK. Conditional knockout mice reveal distinct functions for the global transcriptional coactivators CBP and p300 in T-cell development. Mol Cell Biol. 2006; 26:789-809.

39. Yuan T, Cantley L. PI3K pathway alterations in cancer: variations on a theme. Oncogene. 2008; 27:5497-5510.

40. Parsons DW, Wang T-L, Samuels Y, Bardelli A, Cummins JM, DeLong L, Silliman N, Ptak J, Szabo S, Willson JK. Colorectal cancer: mutations in a signalling pathway. Nature. 2005; 436:792-792.

41. Cantley LC. The phosphoinositide 3-kinase pathway. Science. 2002; 296:1655-1657.

42. Carpenter G, Lembach KJ, Morrison M, Cohen S. Characterization of the binding of 125-I-labeled epidermal growth factor to human fibroblasts. J Biol Chem. 1975; 250:4297-4304.

43. Stern D, Heffernan P, Weinberg R. p185, a product of the neu proto-oncogene, is a receptorlike protein associated with tyrosine kinase activity. Mol Cell Biol. 1986; 6:1729-1740.

44. Plowman GD, Whitney GS, Neubauer MG, Green JM, McDonald VL, Todaro GJ, Shoyab M. Molecular cloning and expression of an additional epidermal growth factor receptor-related gene. Proc Natl Acad Sci U S A. 1990; 87:4905-4909.

45. Plowman GD, Culouscou J-M, Whitney GS, Green JM, Carlton GW, Foy L, Neubauer MG, Shoyab M. Ligandspecific activation of HER4/p180erbB4, a fourth member of the epidermal growth factor receptor family. Proc Natl Acad Sci U S A. 1993; 90:1746-1750.

46. Clayton AH, Orchard SG, Nice EC, Posner RG, Burgess AW. Predominance of activated EGFR higher-order oligomers on the cell surface. Growth Factors. 2008; 26:316-324.

47. Graus-Porta D, Beerli RR, Daly JM, Hynes NE. ErbB-2, the preferred heterodimerization partner of all ErbB receptors, is a mediator of lateral signaling. EMBO J. 1997; 16:1647-1655.

48. Garrett TP, McKern NM, Lou M, Elleman TC, Adams TE, Lovrecz GO, Kofler M, Jorissen RN, Nice EC, Burgess AW. The crystal structure of a truncated ErbB2 ectodomain reveals an active conformation, poised to interact with other ErbB receptors. Mol Cell. 2003; 11:495-505.

49. Uribe P, Gonzalez S. Epidermal growth factor receptor (EGFR) and squamous cell carcinoma of the skin: molecular bases for EGFR-targeted therapy. Pathol Res Pract. 2011; 207:337-342.

50. Ohgaki H. Genetic pathways to glioblastomas. Neuropathology. 2005; 25:1-7. 
51. Ferrara N. Molecular and biological properties of vascular endothelial growth factor. J Mol Med. 1999; 77:527-543.

52. Hicks DG, Short SM, Prescott NL, Tarr SM, Coleman KA, Yoder BJ, Crowe JP, Choueiri TK, Dawson AE, Budd GT. Breast cancers with brain metastases are more likely to be estrogen receptor negative, express the basal cytokeratin CK5/6, and overexpress HER2 or EGFR. Am J Surg Pathol. 2006; 30:1097-1104.

53. Ren S-y, Bolton E, Mohi MG, Morrione A, Neel BG, Skorski T. Phosphatidylinositol 3-kinase p85 $\alpha$ subunitdependent interaction with $\mathrm{BCR} / \mathrm{ABL}$-related fusion tyrosine kinases: molecular mechanisms and biological consequences. Mol Cell Biol. 2005; 25:8001-8008.

54. Shekar SC, Wu H, Fu Z, Yip S-C, Cahill SM, Girvin ME, Backer JM. Mechanism of constitutive phosphoinositide 3-kinase activation by oncogenic mutants of the p85 regulatory subunit. J Biol Chem. 2005; 280:27850-27855.

55. Yin Y, Terauchi Y, Solomon GG, Aizawa S, Rangarajan P, Yazaki Y, Kadowaki T, Barrett JC. Involvement of p85 in p53-dependent apoptotic response to oxidative stress. Nature. 1998; 391:707-710.

56. Storck S, Shukla M, Dimitrov S and Bouvet P. Functions of the histone chaperone nucleolin in diseases. Subcell Biochem. 2007; 41:125-144.

57. Legrand D, Vigie K, Said EA, Elass E, Masson M, Slomianny MC, Carpentier M, Briand JP, Mazurier J, Hovanessian AG. Surface nucleolin participates in both the binding and endocytosis of lactoferrin in target cells. Eur J Biochem. 2004; 271:303-317.

58. Srivastava M, Pollard HB. Molecular dissection of nucleolin's role in growth and cell proliferation: new insights. FASEB J. 1999; 13:1911-1922.

59. Takagi M, Absalon MJ, McLure KG, Kastan MB. Regulation of p53 translation and induction after DNA damage by ribosomal protein L26 and nucleolin. Cell. 2005; 123:49-63.

60. Soundararajan S, Chen W, Spicer EK, Courtenay-Luck N, Fernandes DJ. The nucleolin targeting aptamer AS1411 destabilizes Bcl-2 messenger RNA in human breast cancer cells. Cancer Res. 2008; 68:2358-2365.

61. Zhang J, Tsaprailis G, Bowden GT. Nucleolin stabilizes Bcl-XL messenger RNA in response to UVA irradiation. Cancer Res. 2008; 68:1046-1054.

62. Storck S, Thiry M, Bouvet P. Conditional knockout of nucleolin in DT40 cells reveals the functional redundancy of its RNA-binding domains. Biol Cell. 2009; 101:153-171.

63. Ugrinova I, Monier K, Ivaldi C, Thiry M, Storck S, Mongelard F, Bouvet P. Inactivation of nucleolin leads to nucleolar disruption, cell cycle arrest and defects in centrosome duplication. BMC Mol Biol. 2007; 8:66.

64. Destouches D, El Khoury D, Hamma-Kourbali Y, Krust B, Albanese P, Katsoris P, Guichard G, Briand JP, Courty J, Hovanessian AG. Suppression of tumor growth and angiogenesis by a specific antagonist of the cell-surface expressed nucleolin. PloS one. 2008; 3:e2518.

65. Bates PJ, Choi EW, Nayak LV. G-rich oligonucleotides for cancer treatment. Methods Mol Biol. 2009; 542:379-92.

66. Rosenberg JE, Bambury RM, Van Allen EM, Drabkin HA, Lara Jr PN, Harzstark AL, Wagle N, Figlin RA, Smith GW, Garraway LA. A phase II trial of AS1411 (a novel nucleolintargeted DNA aptamer) in metastatic renal cell carcinoma. Invest New Drugs. 2014; 32:178-187.

67. Li L, Hou J, Liu X, Guo Y, Wu Y, Zhang L, Yang Z. Nucleolin-targeting liposomes guided by aptamer AS1411 for the delivery of siRNA for the treatment of malignant melanomas. Biomaterials. 2014; 35:3840-3850.

68. Farin K, Schokoroy S, Haklai R, Cohen-Or I, Elad-Sfadia G, Reyes-Reyes ME, Bates PJ, Cox AD, Kloog Y, PinkasKramarski R. Oncogenic synergism between ErbB1, nucleolin, and mutant Ras. Cancer Res. 2011; 71:2140-2151.

69. Guhaniyogi J, Brewer G. Regulation of mRNA stability in mammalian cells. Gene. 2001; 265(1):11-23.

70. Bevilacqua A, Ceriani MC, Capaccioli S, Nicolin A. Posttranscriptional regulation of gene expression by degradation of messenger RNAs. J Cell Physiol. 2003; 195:356-372.

71. Manjithaya RR, Dighe RR. The $3^{\prime}$ untranslated region of bovine follicle-stimulating hormone $\beta$ messenger RNA downregulates reporter expression: involvement of AU-rich elements and transfactors. Biol Reprod. 2004; $71: 1158-1166$.

72. Balmer L, Beveridge D, Jazayeri J, Thomson A, Walker C, Leedman P. Identification of a novel AU-Rich element in the $3^{\prime}$ untranslated region of epidermal growth factor receptor mRNA that is the target for regulated RNA-binding proteins. Mol Cell Biol. 2001; 21:2070-2084.

73. Zhang D, Li J, Zhang M, Gao G, Zuo Z, Yu Y, Zhu L, Gao J, Huang C. The requirement of c-Jun N-terminal kinase 2 in regulation of hypoxia-inducing factor- $1 \alpha$ mRNA stability. J Biol Chem. 2012; 287:34361-34371.

74. Mazroui R, Di Marco S, Clair E, von Roretz C, Tenenbaum SA, Keene JD, Saleh M, Gallouzi I-E. Caspase-mediated cleavage of HuR in the cytoplasm contributes to pp32/PHAP-I regulation of apoptosis. J Cell Biol. 2008; 180:113-127.

75. Zhu J, Zhang J, Huang H, Li J, Yu Y, Jin H, Li Y, Deng X, Gao J, Zhao Q. Crucial Role of c-Jun Phosphorylation at Ser63/73 Mediated by PHLPP Protein Degradation in the Cheliensisin A Inhibition of Cell Transformation. Cancer Prev Res. 2014; 7:1270-1281.

76. Huang H, Ma L, Li J, Yu Y, Zhang D, Wei J, Jin H, Xu D, Gao J, Huang C. NF- $\mathrm{B} 1$ inhibits c-Myc protein degradation through suppression of FBW7 expression. Oncotarget. 2014; 5:493. doi: 10.18632/oncotarget.1643.

77. Yu Y, Zhang D, Huang H, Li J, Zhang M, Wan Y, Gao J, Huang C. NF- $\kappa$ B1 p50 promotes p53 protein translation through miR-190 downregulation of PHLPP1. Oncogene. 2014; 33:996-1005. 
78. Zhang D, Wang Y, Liang Y, Zhang M, Wei J, Zheng X, Li F, Meng Y, Zhu NW, Li J. Loss of p27 upregulates MnSOD in a STAT3-dependent manner, disrupts intracellular redox activity and enhances cell migration. J Cell Sci. 2014; 127:2920-2933.
79. Zhang D, Liang Y, Xie Q, Gao G, Wei J, Huang H, Li J, Gao J, Huang C. A Novel Post-Translational Modification of Nucleolin, SUMOylation at K294, Mediates Arseniteinduced Cell Death by Regulating gadd45a mRNA Stability. J Biol Chem. 2015; 290:4784-4800. 